\title{
Bridging The Health Equity Gap : A Case for Using Medical Resources More Effectively
}

\author{
Sujay Chore \\ Undergraduate student (3rd year, Business Studies) \\ Double major in Management Information Systems and Business Analytics \\ Florida International University \\ E-mail: sujaychore1799@gmail.com
}

\begin{abstract}
Firstly, hear me carefully, I want you all to rewind your lives back to when you were 17 years old. Now think about a situation where you are sitting impatiently with your father outside the doctor's cabin, in a hospital as big as this, seeing him study your grandmother's reports; your grandmother being 85 years old and having blood cancer. After sometime, the doctor comes out and points out that your grandmother's case is so serious that operating on her at such an age would at best prolong her life by 6 months, and even so, she would be bed ridden for the rest of her life. He also draws attention to all the resources your family would have to spend on her during these 6 months. Given the circumstances, he recommends that she should not undergo an operation. This way, she can subsequently live peacefully for as long as she can. The prospect of simply "letting your grandmother be" seems so absurd in this case, doesn't it? After all, you can't put a price on your loved one's life.
\end{abstract}

Now rewind your life back by 2 more years. Imagine a situation where you are on a vacation with your family to Africa and while travelling through Nigeria you find out that one of the leading causes of deaths here is something as trivial and easily curable as Malaria. You wonder genuinely, what might be the reason behind this and the answer is quite simply the lack of resources.

Now, knowing what all those resources mean in saving the lives of children in Nigeria, it becomes much more difficult to answer the question of whether you should use the resources to prolong the life of your grandmother or just 'let her be'?

I found myself in this situation less than 4 years ago. The prominence of health equity gap was exemplified in an instant and I started seeking the right answers.

To seek those right answers, I turned to some Scholars of Bioethics. "Well, Bioethics like any ethical stream involves philosophy. In this post-modern, multicultural world, there is no way to objectively give right answers since the decisions undertaken by people are based off of personal experiences", they said.

Many experts still hold this worldview but there is a fundamental flaw in this subjectivism doctrine. We live in a very different world today. Until a century ago, moral philosophy had no direct consequences as such. Philosophy as a whole was looked at solely as an academic field. Today, however, it has very real consequences.

Whether we decide it is ethical to abort a baby in the third trimester or whether it is ethical to kill a person who is terminally ill and no longer wishes to receive treatment or whether it is ethical to donate organs- all of these decisions have very real consequences. 
The notion that everything is subjective and we cannot make objective claims about issues in Bioethics is absurd. I would grant that subjective experiences exist, but we surely can make objective claims about those subjective experiences.

To give you an example, we don't know what Mahatma Gandhi was thinking at the time he was shot. That is a very subjective situation and we do not have any data to find the truth. However, we can certainly make the objective claim that he was not thinking about whether or not our 14th Prime Minister be eating mangoes.

Similarly, in the field of Bioethics, we could make such objective observations on subjective experiences and the way to do it is consequentialism. The only reliable way to make more and more ethically sound decisions is to analyze the possible consequences of a given action and then base our decisions on it. There is an urgent need to shift our philosophical thinking from absolutism to consequentialism if we really do intend to bridge the health equity gap in an unequal and culturally diverse world.

In the field of Bioethics, we can look at it from three perspectives. Individual's, medical doctor's and public policies.

On an individual level, Pneumonia used to be called "the old man's friend" because it often brought a swift and relatively painless end to a life that was already of poor quality, which otherwise would have continued to decline. The study, carried out by Erika D'Agata and Susan Mitchell and published in the Archives of Internal Medicine, showed that over 18 months, twothirds of 214 severely demented patients in nursing homes were treated with antibiotics [1]. We, as individuals, must ask ourselves, whether we should invest all our resources on ourselves and our loved ones, while being aware of the fact that it would not lead to any significant improvement in our quality of life. Even if we assume that antibiotics would prolong the life. The question is, how many people want to prolong their lives? Considering they will be bed ridden and would be needed to be fed by others, with their mental abilities deteriorating irreversibly. If the primary objective is a patient's interests, I am not sure if it's clear that prolonged life is in the best interest of every patient.

From a doctor's perspective, let us take the case of Amillia Taylor. Amillia was termed as the "miracle baby" because she is the most prematurely born surviving baby, born at a gestational age of 21 weeks and 6 days [2]. The baby was understandably weak and it was predicted that she would have severe disabilities while growing up. Instead of discussing the possible option of terminating the baby and taking the nobel active measure, the hospital devoted much of its resources in saving the baby. I am not advocating that all the prematurely born babies with high likelihood of disabilities should be terminated but as doctors, it is their prime responsibility to present these facts, as they are, to parents and let them reasonably decide whether they don't want to take that risk, or put the public to the considerable expense of doing everything possible to ensure the survival of their tiny newborn.

The most important perspective to consider here is the public policy perspective. The medical cost of terminally ill patients with Alzheimer's disease accounted for $\$ 160$ billion in 2010 in the United States. To put this in perspective, the entire foreign aid budget of the United States in 2005 was $\$ 27$ billion [3]. Treating dying patients who do not wish to live any longer is a waste of valuable resources, yet only a few countries allow physician assisted suicide or euthanasia in the world.

While looking for solutions, it is quite clear to me that we need to replace the principles of Beneficence and Non-maleficence with the principle of maximizing human wellbeing. To put it in Sam Harris's words, "the problem of ethics and morality is a navigation problem. We live in a space of infinite possibilities, where one possibility is pure suffering with no silver lining and we have to navigate our ways such that we minimize that suffering and maximize human wellbeing." 
[4]. It is not evident to me, if the principles of Beneficence and Non-maleficence, if applied in their absolute forms, without taking into account all the possible consequences, would lead to maximum human well-being.

The most crucial solution however, is human conversation. We need to be able to have these conversations amongst ourselves and ask these tough questions to our policy makers if we wish to bridge that health equity gap.

To end this, I apologize to have lied in the very beginning. Neither my grandmother had cancer nor had I been to Nigeria. But I did it to present a point in front of you. I had to begin my presentation with a personal story to establish credibility to be eligible to talk about such a serious topic and that is a problem. The notion of Identity politics of only being eligible to talk on certain topics, if and only if you have gone through such experiences is a huge impediment to human flourishing. To rise above the evils of post modernism and moral relativism in Bioethics, we must first fight identity Politics. My arguments here must be just as compelling despite the fact that my grandmother did not have cancer or I did visit Nigeria. Only then would we be able to look at this world as a whole and bridge the health equity gap.

\section{REFERENCES}

1. D'Agata E. Patterns of Antimicrobial Use Among Nursing Home Residents with Advanced Dementia. Arch Intern Med 2008;168(4):357-9.

2. Edemariam A. The extraordinary story of the most premature baby to have ever survived [Internet]. the Guardian. 2019 [cited 13 June 2019]. Available from: https://www.theguardian.com/society/2007/feb/21/health.lifeandhealth

3. Singer P. Ethics in the real world. Princeton University Press; 2016.

4. Harris S. The moral landscape. Free Press; 2014.

Acknowledgements - Nil

Source of Funding - Nil

Conflict of Interest - Nil 